\title{
SOLOS FRÁGEIS DO PARQUE NACIONAL DA SERRA DA CAPIVARA, PIAUÍ
}

\author{
Gustavo Souza Valladares* \\ Universidade Federal do Piauí \\ Cláudia Maria Sabóia de Aquino** \\ Universidade Federal do Piauí \\ Renê Pedro de Aquino*** \\ Universidade Estadual do Piauí \\ Raphael Moreira Beirigo**** \\ Universidade Federal da Paraíba
}

Resumo: O Parque Nacional da Serra da Capivara (PNSC) tem alguns dos sítios arqueológicos mais importantes das Américas. A área onde os solos foram amostrados corresponde ao Parque Nacional da Serra da Capivara (PNSC) e uma área tampão de $10 \mathrm{~km}$ no entorno de seus limites oficiais, no sudeste do Piauí. Para a elaboração do presente trabalho foram selecionados solos considerados frágeis, devido ao alto risco de degradação por erosão, formados de diferentes materiais geológicos representativos do PNSC. Todos os solos estudados são pouco evoluídos, com desenvolvimento pedogenético ainda incipiente, e enquadram-se nas ordens dos Neossolos ou Cambissolos. O bioma representativo da área de estudo é a caatinga, que pela vegetação com pouca biomassa e características decíduas confere pouca cobertura aos solos, aumentando a susceptibilidade dos mesmos à erosão. Foram coletados sete perfis de solos, em diferentes posições na paisagem e formados de materiais de origem. As amostras foram secas ao ar e analisados atributos químicos e granulométricos. Os solos estudados apresentam grandes variações em seus atributos morfológicos, químicos e granulométricos, reflexo dos diferentes materiais de origem. A fragilidade em quase todos os perfis é reflexo da incipiência dos solos, representada pelo baixo grau de agregação e coesão entre as partículas, pequena profundidade e o fator de formação relevo induz na maior erosão de cinco dos sete perfis estudados. Os solos frágeis do PNSC necessitam de cuidados especiais quanto ao manejo, pois alguns deles, principalmente os originários de rochas pelíticas da Formação Pimenteiras, encontram-se em forte processo de degradação, em muitas áreas com as rochas expostas.

Palavras-chave: Conservação do solo. Classificação de solos. Degradação ambiental. Semiárido tropical.

\section{FRAGILE SOILS OF SERRA DA CAPIVARA NATIONAL PARK, PIAUÍ}

Abstract: The Serra da Capivara National Park (PNSC) are some of the most important archaeological sites in the Americas. The area where the soils were sampled corresponds to the PNSC and a buffer area of $10 \mathrm{~km}$ around of its official limits in southeastern of Piauí. For this work were considered fragile soils, due to the high risk of degradation by erosion, formed in different geological materials representative of PNSC. All soils are poorly evolved, with pedogenic development incipient fall in orders of Entisols or Inceptisols. The representative of the study area biome is the caatinga, which vegetation with little biomass and deciduous characteristics, gives little coverage to the soil, increasing susceptibility to erosion. Seven soil profiles were collected at different positions and mother rocks. The soils were classified according to the Brazilian System of Soil Classification (SiBCS). The samples were air dried and analyzed the chemical attributes and texture. The soils vary widely in their morphological, chemical and grain size, reflecting the different source material attributes. The weakness in nearly all profiles reflects the incipient soil, represented by a low degree of aggregation and cohesion between the particles of soil and small depth of relief factor induces the formation of further erosion profiles 5 of the 7 studied. Fragile soils of PNSC require special care in the mangement, because some soils, especially those originating from pelitic rocks by Pimenteiras Formation, are in strong degradation process in many areas with exposed rocks.

Keywords: Soil conservation. Soil classification. Environmental degradation. Tropical semiarid.

\section{SUELOS FRÁGILES DEL PARQUE NACIONAL DE LA SIERRA DE CAPYBARA, PIAUÍ}

Resumen: El Parque Nacional de la Sierra de Capybara (PNSC) tiene algunos de los sitios arqueológicos más importantes de las Américas. El área donde los suelos fueron muestreados corresponde al PNSC y un área tampón de 10km en el entorno de sus límites oficiales, en el sureste del Piauí. Para la elaboración del presente trabajo se seleccionaron suelos considerados frágiles, debido al alto riesgo de degradación por erosión, formados de diferentes materiales geológicos representativos del PNSC. Todos los suelos estudiados son poco evolucionados, con desarrollo pedogenético aún incipiente, y se encuadran en las órdenes de los Neossolos o Cambissolos (en portugués). El bioma representativo del área de estudio es la caatinga, que por la vegetación con poca biomasa y características deciduas, confiere poca cobertura a los suelos, aumentando la susceptibilidad de los mismos a la erosión. Se recogieron muestras de siete perfiles de suelos, en diferentes posiciones en el paisaje y formados de materiales geológicos distintos. Las muestras fueron secas al aire y analizados los atributos químicos y granulométricos. Los suelos estudiados presentan grandes variaciones en sus atributos morfológicos, químicos y granulométricos, reflejo de los diferentes materiales de origen. La fragilidad en casi todos los perfiles es reflejo de la incipiente de los suelos, representada por el bajo grado de agregación y cohesión entre las partículas, pequeña profundidad y el factor de formación relieve induce en la mayor erosión de cinco de los siete perfiles estudiados. Los suelos frágiles del PNSC necesitan cuidados especiales en cuanto al manejo, pues algunos de ellos, principalmente los originarios de rocas pelíticas de la Formación Pimenteiras, se encuentran en fuerte proceso de degradación, en muchas áreas con las rocas expuestas.

Palabras clave: Conservación del suelo. Clasificación de suelos. Degradación ambiental. Semiárido tropical.

\footnotetext{
"Doutor em Ciência do Solo, professor associado e coordenador do curso Geografia do Centro de Ciências Humanas e Letras da UFPI, Campus Universitário Ministro Petrônio Portella, s/n - Ininga, Teresina/PI, 64049-550. E-mail: valladares@ufpi.edu.br

*Doutora em Geografia, professora adjunta do Departamento de Geografia e História do Centro de Ciências Humanas e Letras da UFPI, Campus Universitário Ministro Petrônio Portella, s/n - Ininga, Teresina/PI, 64049-550. E-mail: cmsaboia@gmail.com

${ }_{* \star M}$ Mestre em Geografia, professor assistente da UESPI. UESPI - Campus Clóvis Moura, Rua Desembargador Berilo Mota, s/n - Dirceu Arcoverde I, Teresina/PI, 64078-213. E-mail: rene.uespi@hotmail.com

** Doutor em Ciências - Solos e Nutrição de Plantas, professor adjunto do Departamento de Solos e Engenharia Rural do Centro de Ciências Agrárias da UFPB, Campus II, Rodovia PB 079 km 12 s/n - Universitário, Areia/PB, 58397-000. E-mail: rmbeirigo@yahoo.com.bre
} 
Com a necessidade de preservação dos recursos naturais disponíveis (solo, recursos hídricos, fauna, flora) foram instituídas as Unidades de Conservação (UCs). Nesse contexto, foi criado em 1979 no estado do Piauí o Parque Nacional da Serra da Capivara (PNSC), que ocupa uma área aproximada de 130 mil hectares, inserido no bioma caatinga.

Os Parques Nacionais têm como objetivo básico a preservação de ecossistemas naturais de grande relevância ecológica e beleza cênica, possibilitando a realização de pesquisas científicas e o desenvolvimento de atividades de educação e interpretação ambiental, de recreação em contato com a natureza e de turismo ecológico (BRASIL, 2000).

Segundo Milano (2000), as UCs vêm sendo alvo de vários tipos de pressão por parte das comunidades de entorno, traduzidas na forma de invasões, desmatamentos, extração de produtos, caça e pesca predatória e ainda a expansão de atividades agrícolas, que comprometem a conservação dos recursos naturais. Essa constatação exige que os estudos a serem realizados nas UCs contemplem a área circunvizinha chamada de zona de entorno, a exemplo do presente trabalho, que também inclui solos frágeis do entorno do PNSC - Piauí.

A taxa de erosão do solo é mais influenciada pela declividade do terreno, precipitação, tipo de cobertura, manejo e uso do solo, do que pelos atributos do solo (WISEHMEIER; SMITH, 1978). Porém alguns solos apresentam maiores taxas de erosão do que outros, mesmo quando todos os outros fatores relacionados à erosão são iguais (WISEHMEIER; SMITH, 1978). Essa diferença na susceptibilidade à erosão, devido aos atributos do solo, é definida como erodibilidade do solo (WISEHMEIER; SMITH, 1978; BERTONI; LOMBARDI NETO, 2005).

Uma das principais ameaças ao PNSC é a erosão dos solos no entorno da área do parque. Atividades ligadas à agropecuária que causam a degradação da cobertura vegetal tendem a acelerar o processo de erosão e, consequentemente, de desertificação (AQUINO ET AL., 2012).

O presente trabalho objetivou caracterizar atributos químicos e granulométricos de solos frágeis e incipientes do PNSC e seu entorno, originários dos principais materiais de origem, visando fornecer subsídios para a sua conservação.
O Parque Nacional da Serra da Capivara (PNSC), localizado no sudeste do estado do Piauí (Figura 1), ocupa áreas dos municípios de São Raimundo Nonato, Coronel José Dias, João Costa e Brejo do Piauí (entre os paralelos de 08026'50" e 08054'23" S e meridianos 42o19'47" e 42045'51" 0), com uma área de 129.953ha (GUERIN ET AL., 2002). O clima é do tipo seco (Bsh), segundo a classificação de Köppen (1948), clima semiárido quente, precipitações irregulares com médias anuais de $650 \mathrm{~mm}$ e uma evapotranspiração potencial anual da ordem de $1.400 \mathrm{~mm}$ (BARROS ET AL., 2012). A precipitação concentra-se no mês de outubro e no final de abril, com chuvas, em geral, localizadas e de curta duração. A temperatura média anual é elevada $\left(28^{\circ} \mathrm{C}\right)$, com máxima de $45^{\circ} \mathrm{C}$ e mínima de $12^{\circ} \mathrm{C}$ (GUERIN ET AL., 2002).

A área do PNSC está inserida na bacia sedimentar do Parnaíba, onde ocorrem rochas do tipo arenitos e conglomerados da Formação Cabeças e Serra Grande, micaxisto e calcários metamorfizados do Grupo Bambuí, Formação Barra Bonita com intrusões de granitos, folhelhos, argilitos e siltitos da Formação Pimenteira e sedimentos coluvioaluvionares cenozoicos (BIGARELLA ET AL., 1965; RIODA, ET AL., 2011; BARTORELLI, 2012).

$A$ vegetação na área é de Caatinga, segundo a classificação de Japiassu et al. (1973), e ocorrem as fitofisionomias de Caatinga Arbórea e Caatinga Arbustiva com as variações de densa e aberta, e, segundo IBGE (2012), Savana-Estépica Arborizada e de SavanaEstépica Florestada. As principais classes de solos na área do PNSC são Latossolos, Argissolos, Neossolos Quartzarênicos, Litólicos e Regolíticos (JACOMINE ET AL., 1986a e 1986b).

Foram coletadas 16 amostras de horizontes superficiais e subsuperficiais pertencentes a sete perfis de solos, distribuídos na área de estudo. 0 critério de amostragem dos solos foi a observação no campo de solos susceptíveis a erosão e representativos dos principais materiais geológicos do PNSC. Os solos foram coletados, descritos e caracterizados analiticamente em laboratório, seguindo as recomendações adotadas pela Sociedade Brasileira de Ciência do Solo (EMBRAPA, 1997; SANTOS ET AL., 2005).

A terra fina seca ao ar (TFSA) foi analisada no laboratório da USP/ESALQ e foram caracterizadas, segundo a metodologia da Embrapa (1997), os seguintes atributos químicos e físicos do solo: $\mathrm{pH}$ em água, $\mathrm{pH}$ em solução de $\mathrm{KCl} 1 \mathrm{~N}, \mathrm{~K}^{+}, \mathrm{Na}^{+}, \mathrm{Ca}^{2+}, \mathrm{Mg}^{2+}, \mathrm{Al}^{3+}$ trocáveis, acidez potencial $\left(\mathrm{H}^{+} \mathrm{Al}\right), \mathrm{T}$ (Capacidade de troca catiônica), soma de bases (S), saturação por bases (V\%), saturação por alumínio ( $m \%)$, carbono orgânico (C), Fósforo assimilável $(P)$, areia fina, areia grossa, silte e argila. Os teores de 


\section{FIGURA 1 - MAPA DO BRASIL, ESTADO DO PIAUÍ, PARQUE NACIONAL DA SERRA DA CAPIVARA E LOCALIZAÇÃO DOS SOLOS ESTUDADOS}
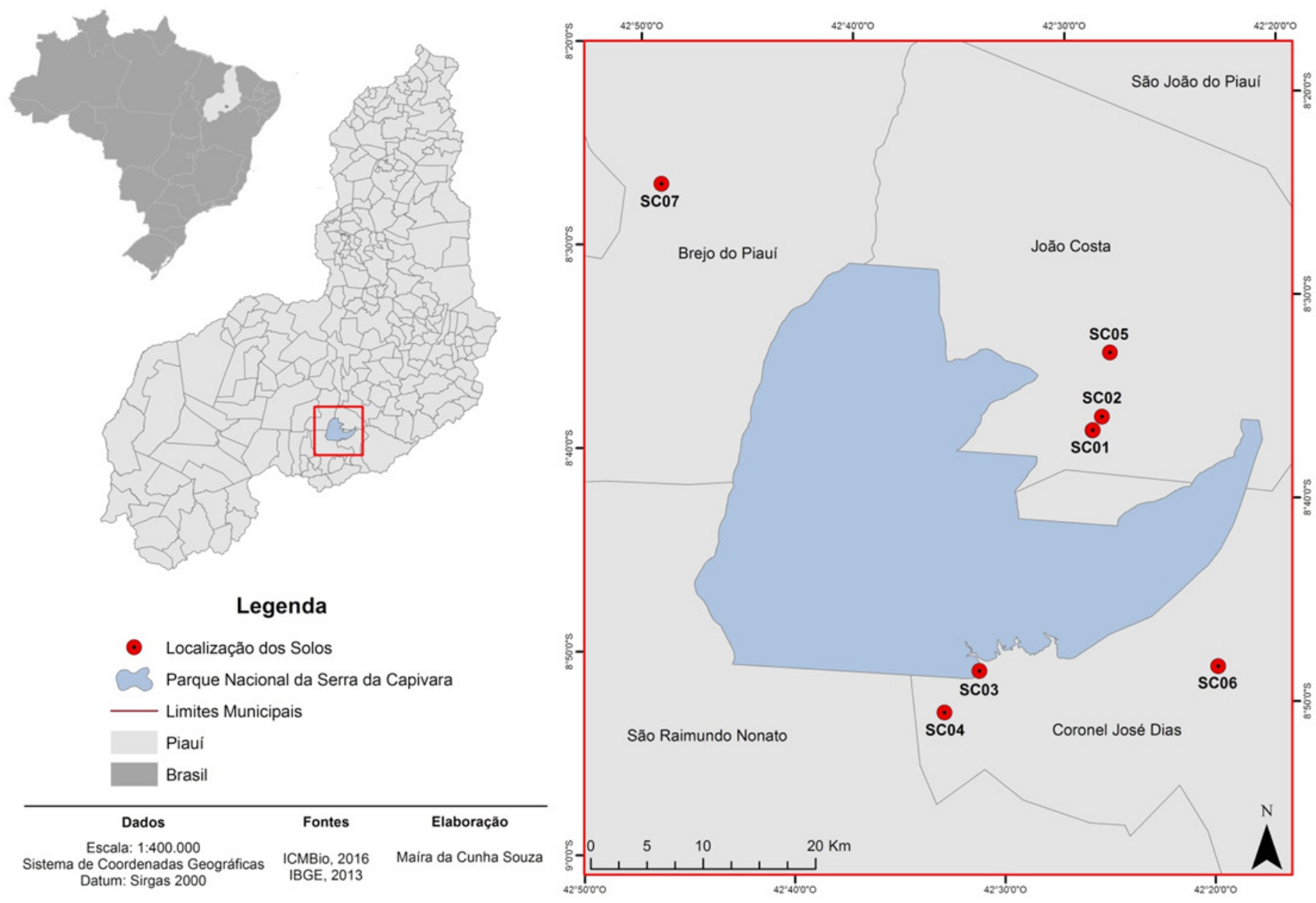

Fonte: organização dos autores.

cascalhos foram quantificados no laboratório de solos e sedimentos da UFPI. A partir da caracterização dos atributos morfológicos, físicos e químicos os solos foram classificados de acordo com o Sistema Brasileiro de Classificação de Solos - SiBCS (EMBRAPA, 2013).

Foram efetuadas análises de correlação de Pearson e interpretação dos dados por meio de diagramas de dispersão. Os coeficientes de correlação tiveram sua significância testada pelo teste $t$ de Student a $5 \%$ de probabilidade.

$\mathrm{Na}$ análise dos componentes principais (ACP) são calculados os fatores que se referem a informações de todas as variáveis pesquisadas, e cada amostra de solo, que era definida pelas variáveis, pode ser definida pelas novas variáveis (fatores), o que possibilita a utilização como ferramenta no agrupamento de variáveis e possíveis correlações.

\section{Resultados e discussão}

Os perfis de solos amostrados e suas características ambientais são mostrados na Figura 2 e no Quadro 1. 
Pl

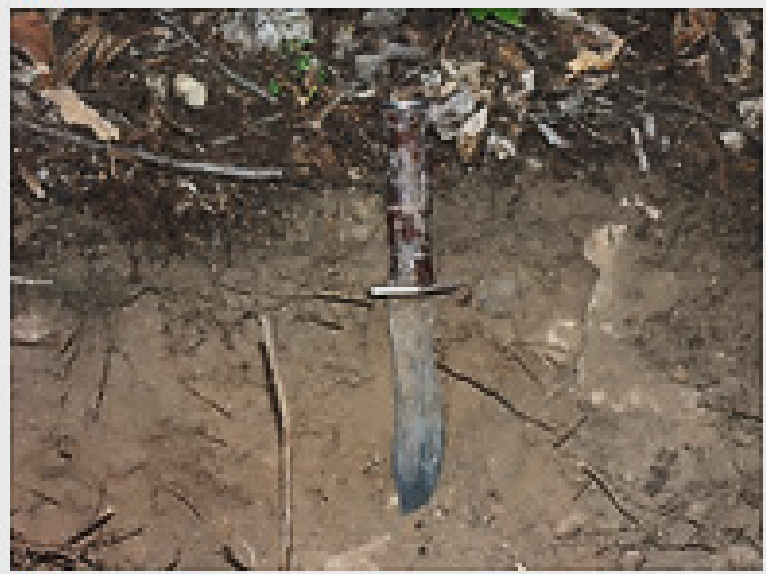

P3

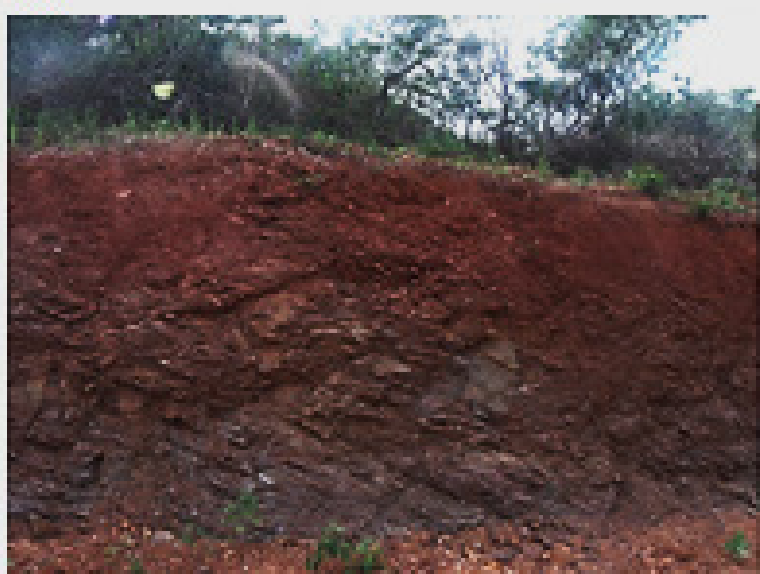

P5

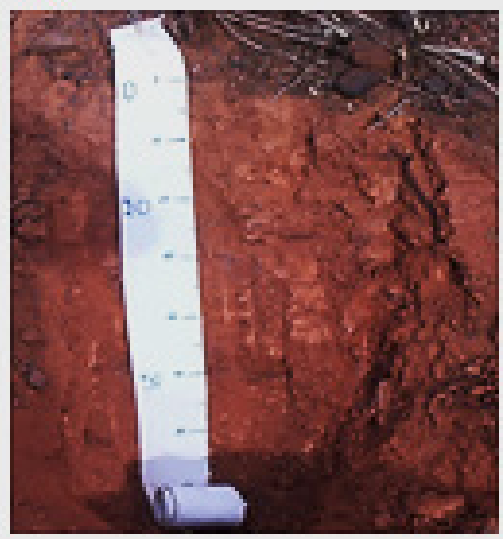

P2

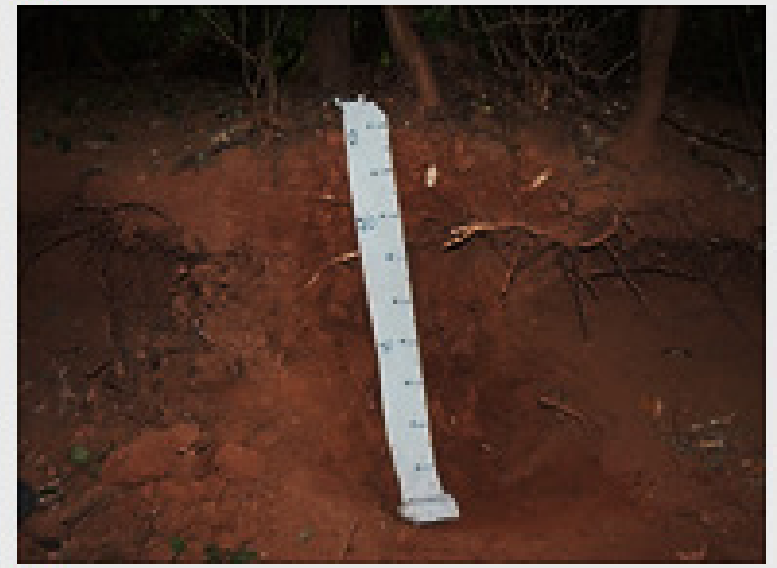

P4

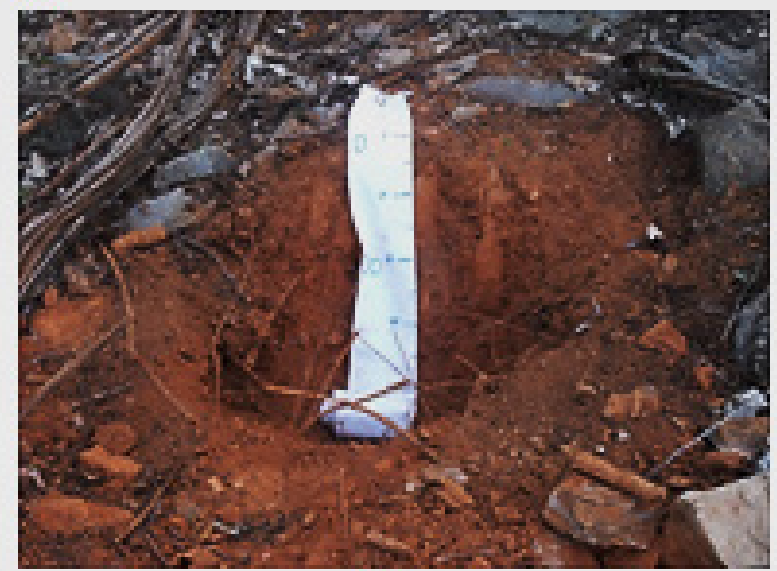

P7
P6

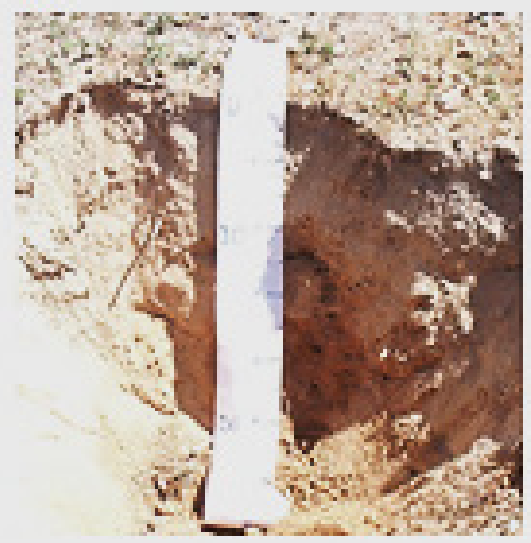

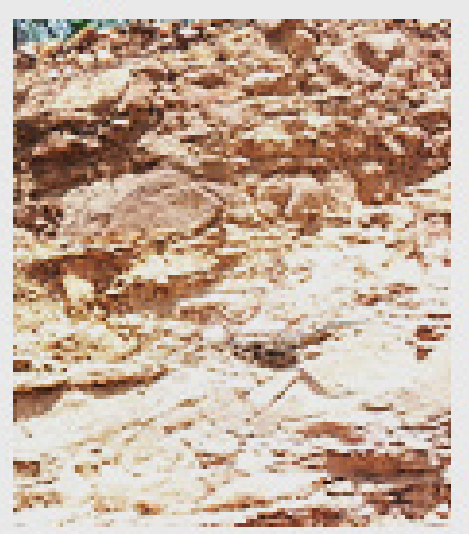

Fonte: organização dos autores.

Tais solos representam os sistemas pedogenéticos de maior fragilidade do PNSC representativos dos materiais geológicos mais abundantes. Dos sete perfis estudados três são da classe dos Neossolos Litólicos, um Neossolo Regolítico e três Cambissolos de acordo com o SiBCS (EMBRAPA, 2013). Cinco dos solos foram descritos e coletados em encostas, com relevo variando de ondulado a fortemente ondulado, um foi coletado no fundo de um vale estreito, sujeito a inundações durante eventos com chuvas intensas, e um foi coletado em pediplano dissecado com relevo colinoso e plano a suave ondulado (Quadro 1). 


\begin{tabular}{|c|c|c|c|c|}
\hline Perfil & Localizaçāo/ ambiente & $\begin{array}{l}\text { Rochosidade/ } \\
\text { pedregosidade }\end{array}$ & $\begin{array}{l}\text { Formaçāo } \\
\text { geológica }\end{array}$ & Erosāo \\
\hline $\begin{array}{l}\text { P1-Neossolo } \\
\text { Litólico } \\
\text { eutrófico típico }\end{array}$ & $\begin{array}{l}780017 \text { W; } 9045835 \text { S; } 318 \mathrm{~m} \text {. } \\
\text { Meia encosta de vales } \\
\text { interplanálticos em relevo forte } \\
\text { ondulado com cobertura de } \\
\text { caatinga arbórea.. }\end{array}$ & $\begin{array}{l}\text { Extremamente } \\
\text { rochoso e } \\
\text { pedregoso. }\end{array}$ & $\begin{array}{l}\text { Arenitos e } \\
\text { conglomerados } \\
\text { do Grupo Serra } \\
\text { Grande. }\end{array}$ & Laminar forte. \\
\hline $\begin{array}{l}\text { P2-Cambissolo } \\
\text { Flúvico } \\
\text { eutrófico típico }\end{array}$ & $\begin{array}{l}780028 \text { W; } 9045855 \mathrm{~S} ; 310 \mathrm{~m} \text {. } \\
\text { Fundo de vale encaixado, ao lado } \\
\text { da rede de drenagem, com relevo } \\
\text { local suave ondulado e cobertura } \\
\text { de capoeira. }\end{array}$ & Ausente. & $\begin{array}{l}\text { Produtos do } \\
\text { intemperismo } \\
\text { de rochas } \\
\text { pelíticas da } \\
\text { Formaçāo } \\
\text { Pimenteiras. }\end{array}$ & $\begin{array}{l}\text { Laminar forte } \\
\text { e em sulcos } \\
\text { com } 0,6 \mathrm{~m} \text { de } \\
\text { profundidade. }\end{array}$ \\
\hline $\begin{array}{l}\text { P3-Neossolo } \\
\text { Litólico } \\
\text { eutrófico } \\
\text { saprolítico }\end{array}$ & $\begin{array}{l}771471 \mathrm{~W} ; 9023381 \mathrm{~S} ; 406 \mathrm{~m} \text {. } \\
\text { Terço inferior de vertente em } \\
\text { relevo forte ondulado com } \\
\text { cobertura vegetal de caatinga } \\
\text { arbustiva arbórea. }\end{array}$ & $\begin{array}{l}\text { Nāo rochoso e } \\
\text { pedregoso. }\end{array}$ & $\begin{array}{l}\text { Micaxistos do } \\
\text { Grupo Casa } \\
\text { Grande, } \\
\text { Formaçāo } \\
\text { Barra. }\end{array}$ & $\begin{array}{l}\text { Laminar } \\
\text { moderada. }\end{array}$ \\
\hline $\begin{array}{l}\text { P4-Cambissolo } \\
\text { Háplico } \\
\text { carbonático } \\
\text { lítico }\end{array}$ & $\begin{array}{l}768660 \text { W; } 9019411 \text { S; } 413 \mathrm{~m} \text {. } \\
\text { Patamar em escarpa de maciço } \\
\text { calcário, com relevo local } \\
\text { ondulado } \\
\text { arbórea/mata seca. }\end{array}$ & $\begin{array}{l}\text { Extremamente } \\
\text { rochoso e } \\
\text { extremamente } \\
\text { pedregoso. }\end{array}$ & $\begin{array}{l}\text { Calcário } \\
\text { metamorfizado } \\
\text { do Grupo } \\
\text { Bambuí, } \\
\text { Formaçāo Barra } \\
\text { Bonita. }\end{array}$ & Laminar forte. \\
\hline $\begin{array}{l}\text { P5-Cambissolo } \\
\text { Háplico } \\
\text { eutrófico } \\
\text { saprolítico }\end{array}$ & $\begin{array}{l}781094 \mathrm{~W} ; 9053009 \mathrm{~S} ; 350 \mathrm{~m} \text {. } \\
\text { Terço médio de encosta de talus, } \\
\text { com relevo forte ondulado e } \\
\text { cobertura e sem cobertura vegetal } \\
\text { devido a forte degradaçāo. }\end{array}$ & $\begin{array}{l}\text { Muito rochoso } \\
\text { er muito } \\
\text { pedregoso. }\end{array}$ & $\begin{array}{l}\text { Rochas pelíticas } \\
\text { da Formaçāo } \\
\text { Pimenteiras }\end{array}$ & $\begin{array}{lr}\text { Laminar forte } \\
\text { e ruitos } \\
\text { sulcos } r \text { de } \\
\text { erosāo, com } \\
\text { exposiçāo do } \\
\text { material de } \\
\text { origem. }\end{array}$ \\
\hline $\begin{array}{l}\text { P6-Neossolo } \\
\text { Regolítico } \\
\text { distrófico } \\
\text { léptico }\end{array}$ & $\begin{array}{l}792263 \text { W; } 9025198 \mathrm{~S}, 344 \mathrm{~m} \text {. } \\
\text { Terço superior de colina em } \\
\text { pediplano dissecado com relevo } \\
\text { plano, com cobertura de caatinga } \\
\text { arbustiva aberta e solo exposto. }\end{array}$ & $\begin{array}{l}\text { Nāo rochoso e } \\
\text { pedregoso. }\end{array}$ & $\begin{array}{l}\text { Rochas ácidas } \\
\text { do Complexo } \\
\text { Sobradinho } \\
\text { Remanso. }\end{array}$ & $\begin{array}{l}\text { Laminar } \\
\text { moderada. }\end{array}$ \\
\hline $\begin{array}{l}\text { P7-Neossolo } \\
\text { Litólico } \\
\text { distrófico } \\
\text { saprolítico }\end{array}$ & $\begin{array}{l}741108 \mathrm{~W} ; 9065716 \mathrm{~S}, 400 \mathrm{~m} \text {. } \\
\text { Terço médio de encosta com } \\
\text { relevo ondulado, com cobertura } \\
\text { de caatinga arbustiva aberta e } \\
\text { solo exposto. }\end{array}$ & $\begin{array}{l}\text { Muito rochoso } \\
\text { e pedregoso. }\end{array}$ & $\begin{array}{ll}\text { Arenito } & \text { da } \\
\text { Formaçāo } & \\
\text { Cabeças. } & \end{array}$ & Laminar forte. \\
\hline
\end{tabular}


O baixo grau de pedogênese dos solos estudados reflete a natureza dos diferentes materiais de origem. 0 evidente desenvolvimento incipiente de seis dos solos, associado a uma paisagem fortemente dissecada, são os principais fatores responsáveis pela fragilidade dos solos estudados. Em todos os solos com maior grau de erosão foi verificada vegetação esparsa, fator que contribui ainda mais para a degradação ambiental. Somente o perfil P3 originário de micaxisto apresentou uma cobertura vegetal mais densa caracterizada por caatinga arbustiva arbórea. Apesar da pequena profundidade desse perfil, o solo é muito poroso e o substrato saprolítico favorece a infiltração das águas das chuvas, minimizando o escoamento superficial e a erosão. Os índices de intemperismo ki, kr, relação silte/argila e a CTC da fração argila não apresentaram correlação significativa entre si, com exceção do ki e kr, e não foram bons indicadores do baixo grau de intemperismo ou desenvolvimento dos solos, pois vários dos solos segundo os índices seriam considerados muito intemperizados.
Os atributos morfológicos dos solos do PNSC (Tabela 1) têm estreita relação com os seus respectivos materiais de origem. Os Neossolos Litólicos originários de rochas psamíticas/psefíticas da Formação Serra Grande (P1) e da Formação Cabeças (P7) apresentam cores amareladas e brunadas, com classe textural areia franca ou franco-arenosa, ambas cascalhentas. São solos que ocupam normalmente as encostas das chapadas com relevo variando de ondulado a escarpado, caracterizando grande parte dos fronts e reversos das cuestas. 0 clima semiárido, o relevo acidentado, a pequena profundidade do solo e a textura grosseira indicam que esses solos têm muito baixo potencial de disponibilidade de água para as plantas, refletindo em uma cobertura vegetal escassa, caracterizada por caatinga arbórea aberta no $\mathrm{P} 1$ e por caatinga arbustiva aberta com muito solo exposto no P7. Portanto, condições pedoclimáticas secas e em uma paisagem com relevo suave ondulado a escarpado que favorece a morfogênese em vez da pedogênese, refletindo em solos pouco desenvolvidos (TRICARD, 1977; CLEMENTE ET AL., 2009), rasos e com rochosidade elevada.

\section{TABELA 1 - ATRIBUTOS MORFOLÓGICOS E FÍSICOS DOS SOLOS DO PNSC E ENTORNO}

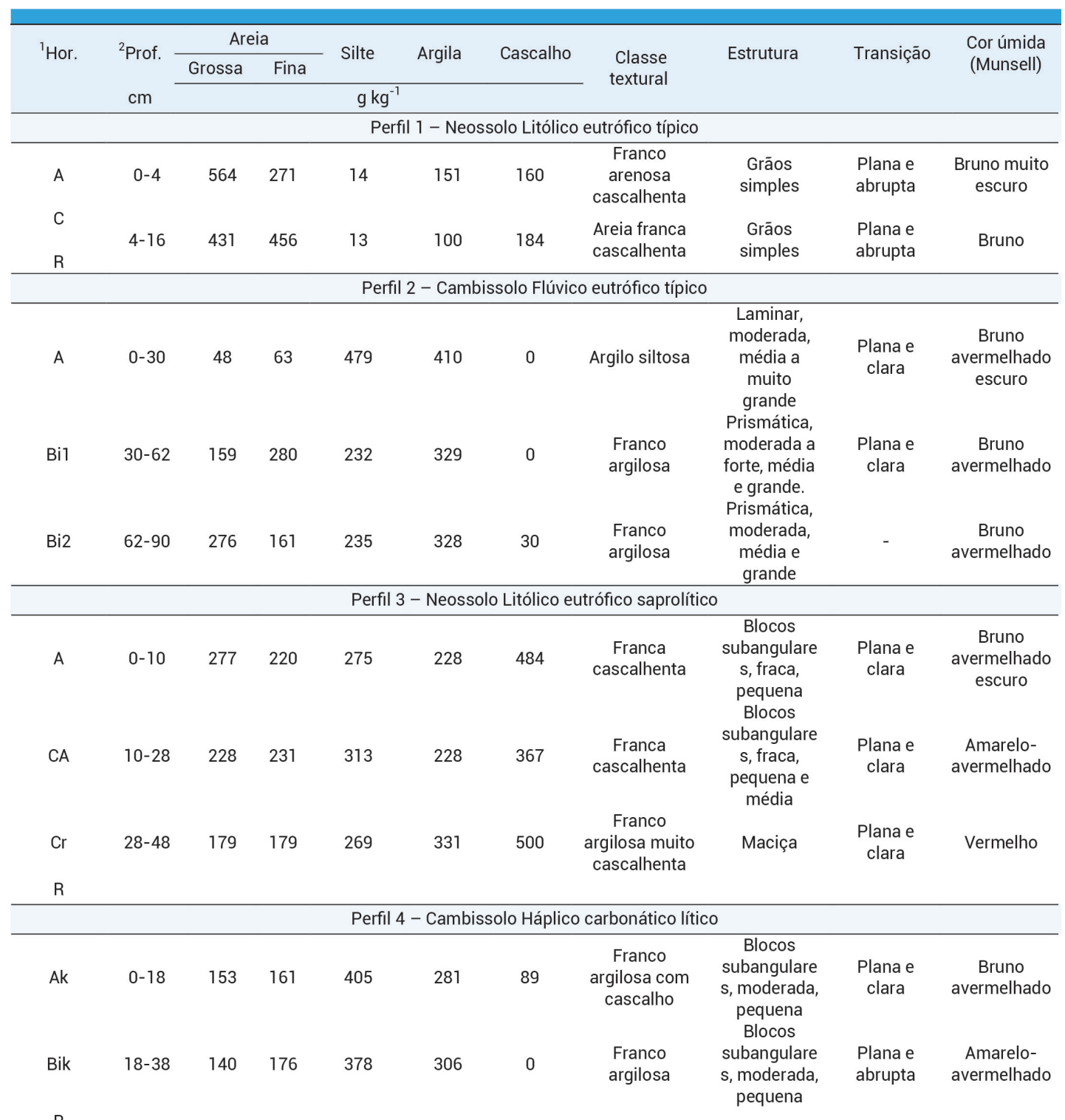


TABELA 1 - ATRIBUTOS MORFOLÓGICOS E FÍSICOS DOS SOLOS DO PNSC E ENTORNO (CONTINUAÇÃO).

\begin{tabular}{|c|c|c|c|c|c|c|c|c|c|c|}
\hline \multirow{3}{*}{${ }^{1} \mathrm{Hor}$. } & \multirow{3}{*}{$\begin{array}{r}{ }^{2} \text { Prof. } \\
\mathrm{cm}\end{array}$} & \multicolumn{2}{|c|}{ Areia } & \multirow[t]{2}{*}{ Silte } & \multirow{3}{*}{ Argila } & \multirow{3}{*}{ Cascalho } & \multirow{3}{*}{$\begin{array}{l}\text { Classe } \\
\text { textural }\end{array}$} & \multirow{3}{*}{ Estrutura } & \multirow{3}{*}{ Transiçāo } & \multirow{3}{*}{$\begin{array}{l}\text { Cor úmida } \\
\text { (Munsell) }\end{array}$} \\
\hline & & Grossa & Fina & & & & & & & \\
\hline & & & & $\mathrm{g} \mathrm{kg}^{-1}$ & & & & & & \\
\hline \multicolumn{11}{|c|}{ Perfil 5 - Cambissolo Háplico eutrófico saprolítico } \\
\hline A & $0-20$ & 75 & 416 & 229 & 280 & 40 & $\begin{array}{c}\text { Franco argilo } \\
\text { arenosa }\end{array}$ & $\begin{array}{c}\text { Blocos } \\
\text { angulares, } \\
\text { moderada, } \\
\text { média } \\
\text { Blocos }\end{array}$ & $\begin{array}{l}\text { Plana } \\
\text { gradual }\end{array}$ & $\begin{array}{c}\text { Bruno } \\
\text { avermelhado }\end{array}$ \\
\hline $\mathrm{Bi}$ & $20-50$ & 27 & 199 & 317 & 457 & 143 & $\begin{array}{l}\text { Argila com } \\
\text { cascalho }\end{array}$ & $\begin{array}{c}\text { angulares e } \\
\text { prismática, } \\
\text { moderada, } \\
\text { média }\end{array}$ & $\begin{array}{l}\text { Plana } \\
\text { gradual }\end{array}$ & $\begin{array}{l}\text { Vermelho } \\
\text { escuro }\end{array}$ \\
\hline $\mathrm{Cr}$ & $50-70^{+}$ & 25 & 135 & 353 & 487 & 459 & $\begin{array}{c}\text { Argila } \\
\text { cascalhenta }\end{array}$ & Maciça & - & $\begin{array}{c}\text { Vermelho } \\
\text { escuro } \\
\text { acinzentado }\end{array}$ \\
\hline \multicolumn{11}{|c|}{ Perfil 6 - Neossolo Regolítico distrófico léptico } \\
\hline A & $0-20$ & 408 & 338 & 153 & 101 & 540 & $\begin{array}{c}\text { Franco } \\
\text { arenosa muito } \\
\text { cascalhenta }\end{array}$ & $\begin{array}{l}\text { Grāos } \\
\text { simples }\end{array}$ & $\begin{array}{l}\text { Plana e } \\
\text { gradual }\end{array}$ & Bruno \\
\hline C & $20-50$ & 277 & 201 & 363 & 159 & 336 & $\begin{array}{c}\text { Franca } \\
\text { cascalhenta }\end{array}$ & Maciça & $\begin{array}{l}\text { Plana e } \\
\text { clara }\end{array}$ & $\begin{array}{l}\text { Variegado } \\
\text { de } \\
\text { vermelho- }\end{array}$ \\
\hline $\mathrm{Cr} *$ & $50-65$ & - & - & - & - & - & $\begin{array}{l}\text { Pedregosa } \\
\text { muito } \\
\text { cascalhenta }\end{array}$ & $\begin{array}{l}\text { Grāos } \\
\text { simples }\end{array}$ & - & $\begin{array}{l}\text { amarelado e } \\
\text { amarelo- } \\
\text { claro- } \\
\text { acinzentado }\end{array}$ \\
\hline $\mathrm{R}$ & $65^{+}$ & & & & & & & & & \\
\hline \multicolumn{11}{|c|}{ Perfil 7 - Neossolo Litólico distrófico saprolítico } \\
\hline $\mathrm{A} / \mathrm{Cr} / \mathrm{R}$ & $0-10$ & 646 & 138 & 40 & 176 & 347 & $\begin{array}{c}\text { Franco } \\
\text { arenosa } \\
\text { cascalhenta }\end{array}$ & $\begin{array}{c}\text { Grāos } \\
\text { simples/ } \\
\text { maciça }\end{array}$ & $\begin{array}{c}\text { Quebrada e } \\
\text { abrupta }\end{array}$ & $\begin{array}{c}\text { Bruno } \\
\text { amarelado } \\
\text { claro }\end{array}$ \\
\hline $\mathrm{Cr} / \mathrm{R}$ & $10-80$ & - & - & - & - & - & - & - & - & - \\
\hline
\end{tabular}

1 = Horizontes; 2 = Profundidade $\mathrm{e}$ = formado por calhaus e cascalhos, nāo foi coletado para análise

Fonte: Barros et al., (2012).

O perfil P3, classificado como Neossolo Litólico, originário de micaxisto, apresentou cores vermelhoamarelas e vermelhas, com classe textural francoargilo-arenosa cascalhenta, localiza-se em terço inferior de vertente com forma convexa. A textura média e a alta porosidade verificada no solo favorecem o estabelecimento de uma vegetação mais densa, caracterizada por caatinga arbustiva arbórea e um menor grau de erosão do solo na área. De todos os solos estudados este é o único que não se encontrava degradado ou erodido excessivamente, apesar de ser um solo raso e também frágil. A remoção da vegetação nativa e o uso agropecuário pode levar à degradação desse solo em um curto período de tempo. O Neossolo Regolítico (P6) tem sequência de horizontes A-C-Cr, com contato lítico a $0,65 \mathrm{~m}$ de profundidade, indicando um solo pouco evoluído. Localiza-se em um pediplano dissecado, com colinas e relevo suave ondulado, sendo o material de origem granito, e o solo tem cores amarelas e vermelho-amarelas. A classe textural é franco-arenosa muito cascalhenta no horizonte A e franca cascalhenta no horizonte $\mathrm{C}$. $\mathrm{O}$ horizonte $\mathrm{Cr}$ é formado basicamente pelas frações calhaus e cascalhos, indicando o intemperismo físico dos granitos em condições pedoclimáticas secas e depressões, como bem destacado por Penteado (1983) em sua obra. Os afloramentos de rocha no ambiente são raros, porém em alguns locais os solos são mais rasos, apresentando contato lítico à profundidade inferior a 0,5m, mas os Neossolos Regolíticos são claramente os predominantes nesse ambiente. A vegetação na área de ocorrência do P6 é muito escassa, caracterizada por caatinga arbustiva aberta, com várias clareiras com solo exposto. A capacidade de suporte desse ambiente é muito baixa, apesar do relevo pouco acidentado, mas com evidente déficit hídrico prolongado devido à classe textural franco-arenosa no horizonte $\mathrm{A}$, franca no $\mathrm{C}$ e o $\mathrm{Cr}$ ser formado por calhaus e cascalhos.

Foram coletados dois Cambissolos Háplicos (P4 e P5) e um Cambissolo Flúvico (P2), os Cambissolos originários de pelitos da Formação Pimenteiras têm cores vermelhas (P2 e P5) e os originários de rochas carbonáticas têm cores vermelho-amarelas (P4). A textura dos Cambissolos variou de média a argilosa, refletindo a textura mais fina dos materiais de origem. 0 perfil P4 originário de rochas carbonáticas ocorre em um patamar de escarpa com relevo local ondulado em ambiente extremamente declivoso e relevo regional escarpado, está localizado a poucos metros de uma caverna típica de calcários, com a presença de espeleotemas, e próximo a sítios arqueológicos abundantes no PNSC (ALMEIDA ET AL., 2012, FONTUGNE ET AL., 2013).

Apesar de o P4 ser um Cambissolo, é muito raso com apenas $0,38 \mathrm{~m}$ para o contato lítico, caracterizado por sequência de horizontes $\mathrm{A}-\mathrm{Bi}-\mathrm{R}$, com estrutura nos dois horizontes pedogenéticos do tipo em blocos e 
com grau moderado, e reação com forte efervescência ao $\mathrm{HCl}$ a $10 \%$, indicando a presença de carbonatos (SANTOS ET AL., 2005). Ferreira (2013), trabalhando com solos da Chapada do Apodi nos estado do CE e RN, também verificou efervescência forte e violenta em solos originários de calcários em ambiente semiárido. A vegetação nativa é caatinga arbustiva aberta, que confere baixa cobertura do solo.

O P5 classificado como Cambissolo Háplico originário de rochas pelíticas da Formação Pimenteiras é o solo mais erodido e degradado dentre os pesquisados, em boa parte da encosta onde ocorre houve decapitação do horizonte $\mathrm{A}$ e até do $\mathrm{B}$, expondo o horizonte $\mathrm{Cr}$ ou a própria rocha. Na região de Gilbués/PI, há solos muito degradados, com alta erodibilidade natural em que a literatura relaciona a ocorrência de siltitos (SALES, 2003; SILVA ET AL., 2011; SILVA, 2013). Outros autores relacionam altos teores de silte com a erodibilidade dos solos (RESENDE, 1985; CLEMENTE ET AL, 2009). No caso do perfil $\mathrm{P} 5$, há baixa coesão entre as partículas do pelito, que se desagrega, e devido à declividade e à ação das chuvas sofre erosão e formação de sulcos, ravinas e voçorocas. A cobertura vegetal é esparsa com vegetação nativa do tipo caatinga arbustiva aberta e solo exposto. Esse ambiente necessita de intervenção, com técnicas de recuperação de áreas degradadas para poder se regenerar.

Quanto aos atributos químicos, a maioria dos solos reflete o caráter eutrófico dos ambientes semiáridos e com moderada ou boa disponibilidade de nutrientes para a maioria das amostras (RAIJ ET AL., 1997). Os perfis $\mathrm{P} 6$ e $\mathrm{P} 7$ foram os menos férteis quando comparados aos demais solos, sendo os únicos distróficos e com baixos teores de nutrientes, originários respectivamente de rocha ácida do tipo granito e de arenito.

Os solos estudados, de forma geral, apresentaram caráter neutro ao se analisar os valores de $\mathrm{pH}$ em água com valores de média e mediana de 6,0 e coeficiente de variação relativamente baixo e igual a $10 \%$. A maioria das amostras (81\%) apresentou valores de $\mathrm{pH}$ entre 5,5 e 6,0, considerados ideais para o desenvolvimento de vegetais superiores (Tabela 2). Somente uma amostra tem $\mathrm{pH}$ em água de 4,8, considerada mais ácida. Os valores de $\mathrm{pH}$ em água apresentaram correlação positiva e significativa com os atributos $\mathrm{pH}$ em $\mathrm{KCl}(\mathrm{r}=0,81), \mathrm{Ca}^{2+}$ $(r=0,84)$, saturação por bases $(r=0,83)$, valor $T(r=0,71)$, valor S $(0,77), P(r=0,57)$ e MnO $(r=0,82)$ (Tabela 3). A correlação foi negativa com os atributos acidez potencial $(r=-0,68)$ e $\mathrm{Al}^{3+}(r=-0,51)$.

TABELA 2 - ATRIBUTOS QUÍMICOS DOS SOLOS DO PNSC E ENTORNO

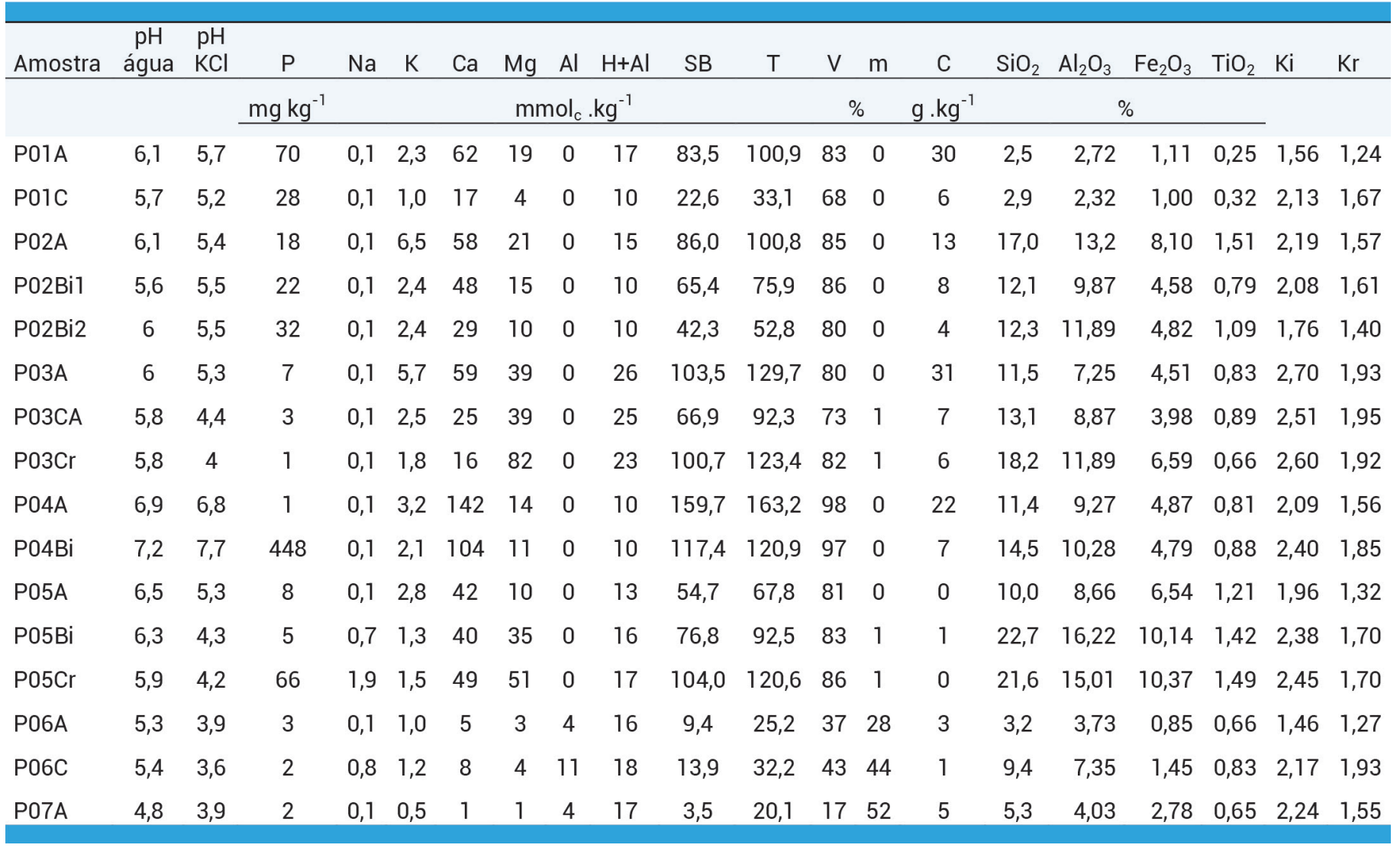

A correlação positiva dos valores de $\mathrm{pH}$ com os teores de $\mathrm{Ca}^{2+}$, soma de bases e saturação por bases deve-se a maior proporção de cátions básicos ocupando os sítios de troca dos solos em comparação aos cátions geradores da acidez do solo como $\mathrm{H}^{+}$e $\mathrm{Al}^{3+}$. 
TABELA 3 - MATRIZ DE CORRELAÇÕES ENTRE OS ATRIBUTOS DOS SOLOS ESTUDADOS.

\begin{tabular}{|c|c|c|c|c|c|c|c|c|c|c|c|c|c|c|c|c|}
\hline & Areia & Silte & Argila & pH água & $\mathrm{Na}$ & $\mathrm{Al}$ & SB & $\mathrm{T}$ & V & $\mathrm{SiO}_{2}$ & $\mathrm{Al}_{2} \mathrm{O}_{3}$ & $\mathrm{Fe}_{2} \mathrm{O}_{3}$ & $\mathrm{TiO}_{2}$ & $\mathrm{MnO}$ & $\mathrm{Ki}$ & $\mathrm{Kr}$ \\
\hline Areia & 1,00 & $-0,92$ & $-0,89$ & $-0,49$ & $-0,42$ & 0,23 & $-0,60$ & $-0,60$ & $-0,58$ & $-0,91$ & $-0,93$ & $-0,85$ & $-0,85$ & $-0,50$ & $-0,48$ & $-0,36$ \\
\hline Silte & - & 1,00 & 0,65 & 0,49 & 0,29 & $-0,01$ & 0,56 & 0,56 & 0,48 & 0,74 & 0,75 & 0,61 & 0,72 & 0,58 & 0,44 & 0,45 \\
\hline Argila & & & 1,00 & 0,40 & 0,49 & $-0,44$ & 0,53 & 0,53 & 0,59 & 0,93 & 0,96 & 0,96 & 0,84 & 0,31 & 0,42 & 0,18 \\
\hline pH água & & & & 1,00 & $-0,07$ & $-0,52$ & 0,77 & 0,71 & 0,83 & 0,36 & 0,39 & 0,38 & 0,28 & 0,82 & 0,12 & 0,03 \\
\hline $\mathrm{Na}$ & & & & & 1,00 & 0,19 & 0,09 & 0,11 & 0,04 & 0,50 & 0,47 & 0,50 & 0,50 & $-0,24$ & 0,25 & 0,21 \\
\hline $\mathrm{Al}$ & & & & & & 1,00 & $-0,58$ & $-0,57$ & $-0,72$ & $-0,31$ & $-0,31$ & $-0,45$ & $-0,16$ & $-0,40$ & $-0,16$ & 0,13 \\
\hline SB & & & & & & & 1,00 & 0,99 & 0,83 & 0,53 & 0,48 & 0,51 & 0,24 & 0,75 & 0,40 & 0,24 \\
\hline $\mathrm{T}$ & & & & & & & & 1,00 & 0,80 & 0,55 & 0,48 & 0,52 & 0,24 & 0,70 & 0,46 & 0,30 \\
\hline V & & & & & & & & & 1,00 & 0,53 & 0,54 & 0,53 & 0,31 & 0,62 & 0,23 & 0,11 \\
\hline $\mathrm{SiO}_{2}$ & & & & & & & & & & 1,00 & 0,97 & 0,92 & 0,79 & 0,34 & 0,63 & 0,47 \\
\hline $\mathrm{Al}_{2} \mathrm{O}_{3}$ & & & & & & & & & & & 1,00 & 0,92 & 0,85 & 0,34 & 0,45 & 0,30 \\
\hline $\mathrm{Fe}_{2} \mathrm{O}_{3}$ & & & & & & & & & & & & 1,00 & 0,86 & 0,31 & 0,49 & 0,19 \\
\hline $\mathrm{TiO}_{2}$ & & & & & & & & & & & & & 1,00 & 0,24 & 0,30 & 0,09 \\
\hline $\mathrm{MnO}$ & & & & & & & & & & & & & & 1,00 & 0,33 & 0,23 \\
\hline Ki & & & & & & & & & & & & & & & 1,00 & 0,89 \\
\hline $\mathrm{Kr}$ & & & & & & & & & & & & & & & & 1,00 \\
\hline
\end{tabular}

Segundo a literatura, os teores de $\mathrm{Al}^{3+}$ em solos com $\mathrm{pH}$ superiores a 5,5 tendem a zero (NACHTIGALL; VAHL, 1989). Os resultados encontrados vão de encontro aos relatos da literatura, uma vez que as únicas três amostras que apresentaram teores de $\mathrm{Al}^{3+}$ superiores a $0,1 \mathrm{cmol}_{\mathrm{c}}$ . $\mathrm{kg}^{-1}$ têm $\mathrm{pH}$ em água inferiores a 5,5. Quanto à acidez potencial, todos os solos tiveram valores inferiores a 0,3 $\mathrm{cmol}_{\mathrm{c}} \cdot \mathrm{kg}^{-1}$, indicando baixa acidez (VALLADARES, 2009).

Em relação aos teores de $\mathrm{K}^{+}$, uma amostra de solo originário de arenito tem valor abaixo de $0,7 \mathrm{mmol}_{\mathrm{c}} \cdot \mathrm{kg}^{-}$ $1,31 \%$ das amostras estão entre 0,7 e $1,5 \mathrm{mmol}_{\mathrm{c}} \cdot \mathrm{kg}^{-1}$, $44 \%$ das amostras estão entre 1,5 e $3,0 \mathrm{mmol}_{\mathrm{c}} \cdot \mathrm{kg}^{-1} \mathrm{e}$ três amostras apresentam valores altos superiores a 3,0 $\mathrm{mmol}_{\mathrm{c}} \cdot \mathrm{kg}^{-1}$ (Raij et al., 1997). Os teores de $\mathrm{K}^{+}$apresentam correlação positiva e significativa a $5 \%$ com valor $\mathrm{T}$ $(r=0,51)$ e CO $(r=0,58)$.

Os teores de $\mathrm{Na}^{+}$em todas as amostras foram muito baixos, próximos a zero, mesmo nas amostras originárias de granitos que são ricos em feldspatos sódicos. Esses teores indicam baixa saturação por sódio, mesmo nesse ambiente semiárido, em que é comum a ocorrência de solos com caráter sódico e solódico (Embrapa, 2013).

O $\mathrm{Ca}^{2+}$ em $31 \%$ das amostras tem teores entre $0,2 \mathrm{e}$ $2,0 \mathrm{cmol}_{\mathrm{c}} \cdot \mathrm{kg}^{-1}$, em $19 \%$ entre 2 e $4 \mathrm{cmol}_{\mathrm{c}} \cdot \mathrm{kg}^{-1}$, em $38 \%$ entre 4 e $8 \mathrm{cmol}_{c} \cdot \mathrm{kg}^{-1}$, e somente os horizontes do P4 apresentaram teores maiores do que $8 \mathrm{cmol}_{\mathrm{c}} \cdot \mathrm{kg}^{-1}$. Esse perfil é originário de calcário, e, como o ambiente pedoclimático favorece as baixas taxas de intemperismo, as concentrações do cátion foram as mais elevadas. Esses teores apresentaram correlação positiva e significativa a $5 \%$ com Valor $\mathrm{T}(r=0,78)$, soma de bases $(r=0,86)$, saturação por bases $(r=0,73), \mathrm{CO}(r=0,52)$ e MnO $(r=0,80)$. A grande maioria das amostras apresenta $\mathrm{Ca}^{2+}$ elevado, segundo a classificação de Raij et al (1997), o que indica não haver deficiências para vegetais superiores (média de 4,4 $\mathrm{cmol}_{\mathrm{c}} \cdot \mathrm{kg}^{-1}$, mediana de $4,1 \mathrm{cmol}_{\mathrm{c}} \cdot \mathrm{kg}^{-1} \mathrm{e}$ coeficiente de variação elevado de $84 \%$ ).

O Valor T ou CTC do solo teve grande variação com valores baixos de $2,0 \mathrm{cmol}_{\mathrm{c}} \cdot \mathrm{kg}^{-1}$ para o perfil P07 originário de arenito da Formação Cabeças e valores elevados para o horizonte superficial do P04 $\left(16,3 \mathrm{cmol}_{c}\right.$ . $\left.\mathrm{kg}^{-1}\right)$, e apresentou correlação positiva com os teores de argila, silte, $\mathrm{pH}$, soma de bases, $\mathrm{C}$, sílica e óxido de manganês. E negativa com os teores de areia e alumínio.

Com base na análise dos componentes principais, em que foram utilizados os seguintes atributos dos solos: areia total, silte, argila, $\mathrm{pH}$ em água, valor $\mathrm{T}$, valor $\mathrm{V}, \mathrm{Na}^{+}, \mathrm{Al}^{3+}$, soma de bases, $\mathrm{SiO}_{2^{\prime}} \mathrm{Fe}_{2} \mathrm{O}_{3^{\prime}}, \mathrm{TiO}_{2^{\prime}} \mathrm{MnO}$, ki e kr, a variabilidade foi explicada em $73 \%$ dos casos segundo o "Engeivalue" pelos fatores 1 e 2. 0 agrupamento das amostras foi eficiente, formando quatro grupos (Figura 3). 


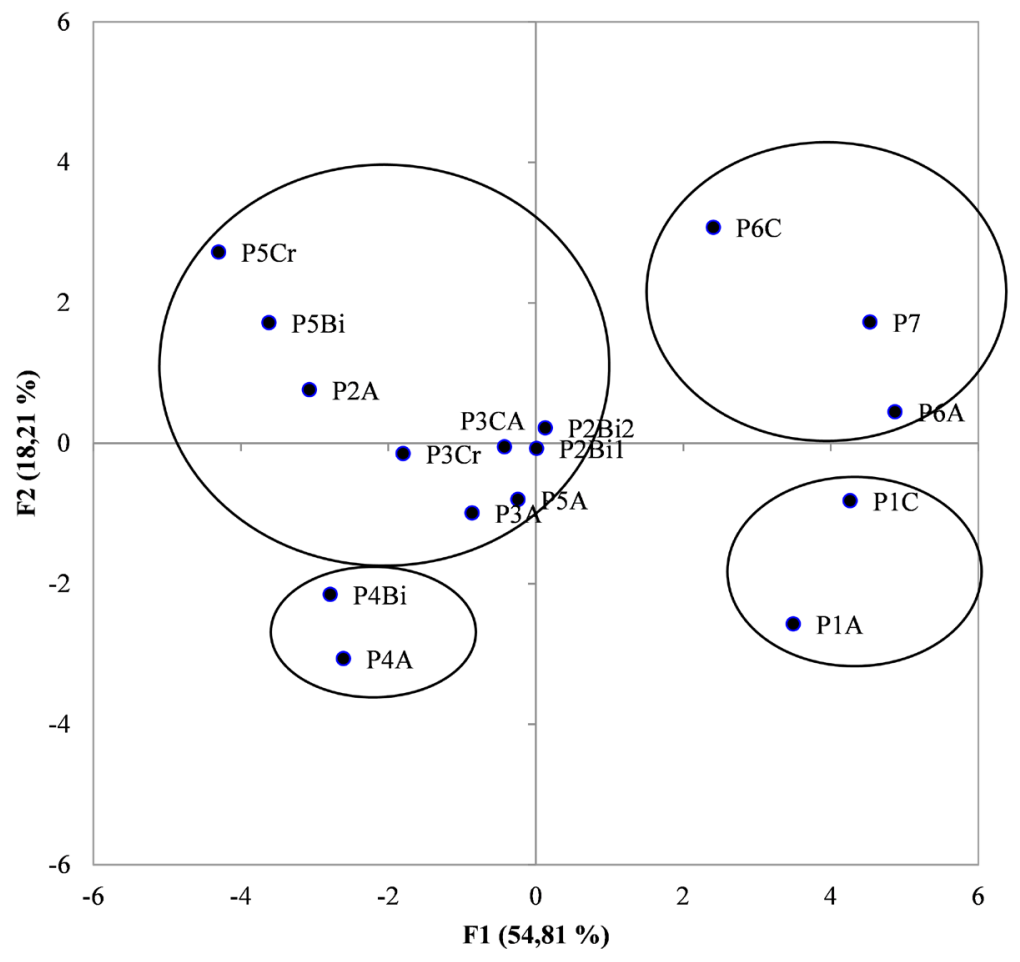

Nos quadrantes 1 e 4, com fatores F1 positivos, está representada a maioria das amostras de textura arenosa, sendo que aquelas com alta saturação por bases (P1) localizam-se no quadrante 4 e as com baixa saturação por bases no quadrante 1 (P6 e P7).

$\mathrm{Na}$ porção central do gráfico e nos quadrantes 2 e 3 , localizam-se as amostras com textura média ou argilosa, sendo que o perfil com maior soma de bases (P4), originário de rochas calcárias, formou um grupo à parte das demais amostras.

\section{Conclusões}

Os solos considerados mais frágeis do PNSC e seu entorno foram classificados como Neossolos ou Cambissolos, sendo todos rasos ou pouco profundos, indicando baixo grau de desenvolvimento pedogenético, principalmente com base na morfologia, já que os índices de intemperismo não foram bons indicadores. Todos os solos estudados apresentam grande fragilidade pela avaliação de diferentes atributos, como a classe textural com predomínio da fração areia, grau de desenvolvimento da estrutura, pedregosidade e rochosidade, principalmente nos horizontes superficiais.

A caracterização e a interpretação dos atributos morfológicos, físicos e químicos do solo com base nos fatores de formação (material de origem, relevo, clima, organismos e o tempo) é uma das melhores formas para estratificar os ambientes terrestres. O SiBCS, por ser um sistema de classificação de solos morfogenético, permite relacionar a formação e o desenvolvimento do solo aos fatores ambientais, e avaliar a suscetibilidade a degradação. As áreas de ocorrência destes solos devem ser manejadas com cuidado, a partir de técnicas que reduzam os impactos ambientais negativos, já que os solos se encontram bastante degradados, com atenção especial aos solos originários de rochas pelíticas da Formação Pimenteiras.

Os planos de manejo das unidades de conservação (UNCs) devem ter como base os mapas de solos das áreas, sendo que o levantamento e o mapeamento são fundamentais para a gestão destas UNCs, por ser o solo a base de sustentação dos diversos ecossistemas terrestres. 
ALMEIDA, V. J. M.; ETCHEBEHERE, M. L. C.; SAAD, A. R.; RAMPANELLI, A. M. (2012) O registro de fauna nas pinturas rupestres do Parque Nacional da Serra da Capivara (PI) e seus prováveis indicadores paleoambientais. Revista UnG Geociências, v. 11, p. 19-58.

AQUINO, C. M. S.; OLIVEIRA, J. G. B.; ALMEIDA, J. A. P de. (2012) Análise da desertificação do núcleo de São Raimundo Nonato Piauí. Revista Brasileira de Cartografia, v. 64, p. 287-299.

BARROS, J. S.; FERREIRA, R. V.; PEDREIRA, A. J.; GUIDON, N. (2012) Geoparque Serra da Capivara-Proposta. In: SCHOBBENHAUS, C.; SILVA, C. R. da. (Orgs.). Geoparques do Brasil: Propostas. 1. ed. Rio de Janeiro: CPRM, p. 493-542.

BARTORELLI, A. (2012) Serra da Capivara. In: HASUI, Y.; CARNEIRO, C. D. R.; ALMEIDA, F. F. M.; BARTORELLI, A. (Orgs.). Geologia do Brasil. São Paulo: BECA, p.395-406.

BERTONI, J.; LOMBARDI NETO, F. (2005) Conservação do solo. 5. ed. São Paulo: Ícone. 355p.

BIGARELLA, J. J.; MABESSONE, J. M.; LINS, C. J. C.; MOTA, F. O. (1965) Paleogeographical features of the Serra Grande and Pimenteira Formations (Parnaíba Basin, Brazil). Palaeogeography, Palaeoclimatology, Palaeoecology, v. 1, p. 259296.

BRASIL. (2000) Lei n. 9.985, de 18 de julho de 2000. Regulamenta o art. 225, § $1^{\circ}$, incisos I, II, III e VII da Constituição Federal, institui o Sistema Nacional de Unidades de Conservação da Natureza e dá outras providências. Disponível em: <http://www.mma.gov.br/estruturas/sbf_dap_cnuc2/_arquivos/snuc.pdf>. Acesso em: 9 dez. 2013.

CLEMENTE, E. P.; SCHAEFER, C. E.; OLIVEIRA, F. S.; ALBUQUERQUE FILHO, M. R.; ALVES, R. J. V.; FIRME SÁ, M. M.; MELO, V. F.; CORRÊA, G. R. (2009) Topossequência de dolos na Ilha da Trindade, Atlântico Sul. Revista Brasileira de Ciência do Solo, v. 33, p. 1.357-1.371.

EMBRAPA - Empresa Brasileira de Pesquisa Agropecuária. (1997) Manual de métodos de análise de solo. EMBRAPA/ SNLCS. Rio de Janeiro. $212 \mathrm{p}$.

(2013) Sistema brasileiro de classificação de solos. 3. ed. Brasília. 353 p.

FERREIRA, E. P. (2013) Gênese e classificação de solos em ambiente cárstico na Chapada do Apodi. Dissertação de Mestrado. UFRRJ.

FONTUGNE, M.; SHAO, Q.; FRANK, N.; THILL, F.; GUIDON, N.; BOEDA, E. (2013) Cross-dating (Th/U-14C) of calcite covering prehistoric paintings at Serra da Capivara National Park, Piaui, Brazil. Radiocarbon, v. 55, p. 1.191-1.198.

GUÉRIN, C; FAURE, M; SIMÕES, P. R; HUGUENEY, M; MOURER-CHAUVIRE, C. (2002) Toca da janela da Barra do Antonião, São Raimundo Nonato/PI. In: DNPM/CPRM/SIGEP. Sítios geológicos e paleontológicos do Brasil. Brasília: DNPM, p. 131-137.

IBGE. (2012) Manual técnico da vegetação brasileira. Rio de Janeiro: IBGE, 2012. 274 p.

JACOMINE, P. K. T. (1986a) Levantamento exploratório-reconhecimento de solos do estado do Piauí. Recife: DPP, AgMA/DNPEA, SUDENE/DRN. (Boletim de pesquisa n. 26).

(1986b) Levantamento exploratório - reconhecimento de solos do estado do Piauí. Recife: DPP, AgMA/DNPEA, SUDENE/DRN. (Boletim Técnico n. 28).

JAPIASSU, A. M. S.; FILHO, L. G.; LEITE, P. F. (1973) Vegetação: estudos fitogeográficos da Folha SB.23 Teresina e Parte da Folha SB.24 Jaguaribe. In:

BRASIL. Ministério de Minas e Energia. Projeto RADAMBRASIL. Rio de Janeiro, v. 2, p. 3-84.

KÖPPEN, W. (1948) Climatologia: con un estudio de los climas de la tierra. México: Fondo de Cultura Econômica. 478 p.

MILANO, M. S. Mitos no manejo de unidades de conservação no Brasil, ou a verdadeira ameaça. In: I Congresso Brasileiro de Unidades de Conservação. Curitiba: IAP/UNILIVRE: rede Pró-Unidades de Conservação. Anais v. 1, p. 11-25.

NACHTIGALL, G.R.; VAHL, L.C. (1989) Parâmetros relacionados à acidez em solos da região sul do Rio Grande do Sul. Revista Brasileira de Ciência do Solo, Viçosa. v.13, n. 2, p. 139-143.

PENTEADO, M. M. (1983) Fundamentos de Geomorfologia. Rio de Janeiro: IBGE. 188 p.

PEREIRA, M. G.; VALLADAES, G. S.; SOUZA, J. M. P. F. e; PEREZ, D. V.; ANJOS, L. H. C. dos. (1998) Parâmetros relacionados à acidez em solos do Estado do Rio de Janeiro. Circular técnica 02, Circular Técnica, Rio de Janeiro: Embrapa CNPS. 14p. Disponível em:<https://ainfo.cnptia.embrapa.br/digital/bitstream/item/88359/1/circulartecnica-02-1998.pdf >. Acesso em: 16 dez. 2013.

RAIJ, B. van; CANTARELLA, H.; QUAGGIO, J. A.; FURLANI, A. M. C. (1997) Recomendações de adubação e calagem para o estado de São Paulo. 2. ed. rev. e atual. Campinas: Instituto Agronômico/Fundação IAC. 285 p. (Boletim Técnico, 100) 
RESENDE, M. (1985) Aplicação de conhecimentos pedológicos à conservação de solos. Informe Agropecuário, Belo Horizonte, v.11, n.128, p.3-18.

RIODA, V.; CANDELATO, F.; MOTA, L.; PARENTI, F. (2011) Jazidas de rochas silicosas na área do Parque Nacional da Serra da Capivara (Piauí, Brasil): primeiros dados geoarqueológicos. Revista Museu Arq. Etn, v. 21, p. 103-113.

SALES, M. C. L. (2003) Degradação Ambiental em Gilbués, Piauí. Revista Mercator. Fortaleza, v. 02, n. 04. p.115-124. SANTOS, R. D.; LEMOS, R. C.; SANTOS, H. G.; KER, J. C.; ANJOS, L. H. C. (2005) Manual de descrição e coleta de solo no campo. 5. ed. Viçosa: SBCS. 100 p.

SANTOS, H. G.; JACOMINE, P. K. T.; ANJOS, L. H. C.; OLIVEIRA, V. A.; OLIVEIRA, J. B.; COELHO, M. R.; LUMBRERAS, J. F.; CUNHA, T. J. F. (2006) Sistema Brasileiro de Classificação de Solos. 2. ed. Rio de Janeiro: Embrapa Solos. 306 p.

SANTOS, H. L., MARQUES JÚNIOR, J., MATIAS, S. S. R., SIQUEIRA, D.S.; MARTINS FILHO, M. V. (2013) Erosion factors and magnetic susceptibility in differet compartments of a slope in Gilbués - PI, Brazil. Engenharia Agrícola, Jaboticabal. V. 33, n.1, p. 64-74.

SILVA, I. A. S.; SILVA, J. C.B.; SILVA, K. A.; BARROS, J.R. (2011) Estudo da Desertificação em Gilbués-Piauí: Caracterização Física, Variabilidade Climática e Impactos Ambientais. Revista de Geografia (UFPE), Recife. v.28, n.2, p. 95 - 108. TRICART, J. (1977) Ecodinâmica. Rio de Janeiro: IBGE. 91 p.

VALLADARES, G. S. (2009) Caracterização química e granulométrica de solos do Golfão maranhense. Acta Amazonica, v. 39, p. 923-933.

WISCHMEIER, W. H.; SMITH, D. D. (1978) Predicting rainfall erosion losses: a guide to conservation planning. Washington, DC: USDA. (Agriculture handbook, 537) 